\title{
Alexandre Afranio Peixoto (1963-2013)
}

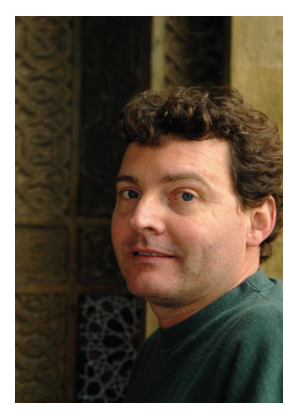

Alexandre Afranio Peixoto, a leading Researcher at Instituto Oswaldo Cruz, died tragically in a rafting accident on February 10, 2013 in Mar d'Espanha, Minas Gerais. He is survived by his wife Valéria and two sons: Daniel (22) and Pedro (17).

Alexandre carried out his undergraduate studies at the Federal University of Rio de Janeiro, during which time he analyzed the chromosome inversion polymorphism of Drosophila mediopunctata in the laboratory of Louis B. Klaczko; work he continued during his Master's degree in the same Institution. He then went to Great Britain to obtain his PhD at the University of Leicester supervised by Charalambos P. Kyriacou studying the molecular evolution of the period gene, which controls the biological clock in Drosophila. Finally, he did his post-doctoral work at Jeffrey C. Hall's laboratory in Brandeis University, U.S.A.

In 1997 Alexandre came back to Brazil to work as a Researcher at Instituto Oswaldo Cruz (Fiocruz) in Rio de Janeiro. After some time, he established the Laboratory of Insect Molecular Biology, working initially on Lutzomyia, the fly that transmits leishmaniasis. Then, he extended his studies to other insect vectors of tropical diseases, such as Aedes aegypti and Culex quinquefasciatus, always using molecular and evolutionary approaches to analyze the genes that control the circadian rhythms and behavior, and their relation to epidemiological and physiological aspects. As a great enthusiast of insect genetics, he also collaborated with other laboratories throughout Brazil and all over the world. He published his work in about 80 scientific papers in prestigious journals, such as Science, PNAS-USA, Trends in Genetics, Genetics, Heredity, among others. He was an International Research Scholar of the Howard Hughes Medical Institute (2002 and in 2007) and a Fellow of the John Simon Guggenheim Memorial Foundation (2003). He supervised 18 students for a Master's degree, 14 $\mathrm{PhD}$ students as well as six post-docs. Presently there are 2 undergraduate, 4 graduate students and 4 post-docs finishing the work started with him.

Alexandre was greatly admired by students and colleagues for his deep biological knowledge, brightness, creativity and methodical work. As a professor or colleague in the lab he was a kind and most easy going person, with a great sense of humor, immense generosity and willingness to cooperate. He would always find the time and means to help students and colleagues. His precocious departure leaves an empty space in Fiocruz, Brazilian Science and Evolutionary Genetics, as well as a sore void in our lives and hearts.

Louis Bernard Klaczko Departamento de Genética, Evolução e Bioagentes, Instituto de Biologia, Universidade Estadual de Campinas, Campinas, SP, Brazil. E-mail: LBK@unicamp.br.

Rafaela V. Bruno Laboratório de Biologia Molecular de Insetos, Instituto Oswaldo Cruz, Rio de Janeiro, Brazil, Instituto Nacional de Ciencia e Tecnologia em Entomologia Molecular, CNPq, Rio de Janeiro, Brazil. E-mail: rafaelav@ioc.fiocruz.br. 